\title{
Traumatic Spinal Cord Injuries in Greenland 1965-1986
}

\author{
V. Pedersen, MD, P. G. Müller, MD, F. Biering-Sørensen, MD, PhD \\ Center for Spinal Cord Injured, Department TH, Rigshospitalet, University \\ Hospital, Denmark.
}

\section{Summary}

During the period 1 fanuary 1965 to 31 December 1986, 27 patients were admitted to the Rehabilitation Hospital in Hornbaek after traumatic spinal cord injury (SCI) sustained in Greenland. The commonest cause of injury was attempted suicide (7 patients), of which 6 were jumps from buildings. Six resulted from accidental falls to a level below and even 2 out of the 3 cases of SCI following violence were due to falls. There was only one traffic injury, a motor cycle accident. Fourteen patients were under the influence of alcohol at time of injury. Nine were tetraplegic ( 3 complete, 6 incomplete), and 18 paraplegic (10 complete, 8 incomplete). Ten regained useful neurological remission. Of the 23 native Greenlanders only 4 paraplegics and 1 tetraplegic remained in their previous residences, 5 resettled in Denmark. At the time of follow-up 17 patients were living alone and only 7 were in work.

Key words: Spinal cord injury; Epidemiology; Social outcome; Greenland.

Greenland, the world's largest island, covers 840000 square miles (2 176000 square $\mathrm{km}$ ) and lies more than two thirds within the Arctic Circle in the North Atlantic Ocean. Greenland's major physical feature is its massive ice sheet with an average thickness of $5000 \mathrm{ft}(1500 \mathrm{~m})$ and covering more than 700000 square miles (nearly $85 \%$ of the total land area). The remaining ice-free land occupies the countries coastal areas and consists largely of highlands. It is still considered to be an integral part of Denmark, but since 1979 has had home rule which includes jurisdiction over the social welfare system, but Denmark provides various welfare services, including the health service. For specialised medical treatment, transfer to Denmark is necessary, to the Rigshospitalet, University Hospital in Copenhagen. Spinal cord injury patients (SCI) after neurosurgical 
evaluation and treatment at the Rigshopitalet are referred to the Center for spinal cord injured in Hornbaek. During the acute phase in the Department of Neurosurgery treatment is conducted in close co-operation with the medical staff from the Center for spinal cord injured.

The population in Greenland was 39600 inhabitants in 1966, 49630 in 1976 and 53406 in 1986 (Statistical Yearbook, 1968, 1977, 1986). The population is primarily situated in the urban areas $(77.8 \%)$ and the rest $(22.2 \%)$ in minor settlements. As a consequence of these geographical conditions the road network is sparsely developed and inter-urban roads are practically non-existent. Outside the cities most transport is by ship, airplane and dog sledge.

Traffic accidents, being the commonest cause at SCI in industrialised countries (Bedbrook, 1982; Kraus, 1980; Kurtske, 1975; Pedersen, 1988) is consequently of lesser importance in Greenland. In spite of this we have found that the total number of SCI in Greenland in the period 1 January 1965 to 31 December 1986 was surprisingly high compared with the incidence in the rest of Denmark in the same period.

We have therefore found it to be of interest to analyse the aetiology and outcome of the SCI patients injured in Greenland in the above-mentioned period.

\section{Patients and methods}

During the 22-year period 1 January 1965 to 31 December 1986, we have received 623 patients with traumatic SCI. Of these 27 were injured in Greenland and transferred for neurosurgical evaluation and treatment and further rehabilitation in Denmark.

Of the 27 patients received for rehabilitation, 1 was admitted 3 years after injury. The rest were all transferred directly from the Neurosurgical Department, Rigshopitalet, University Hospital in Copenhagen, from which Department we have knowledge of a further two SCI patients injured in Greenland between 1 January 1977 and 31 December 1986, but they were not referred for rehabilitation and are therefore excluded from this study.

The classification of Frankel et al. (1969) at the time of admission is based upon information from the Neurosurgical Department records.

\section{Results}

Of the 27 patients, 6 were admitted during the first 11 years and 21 during the last 11 years. Twenty were males, 7 females. The mean age was 33.5 years (range 14-50).

The mean hospitalisation time in Greenland before transferral to the Neurosurgical Department in Copenhagen was 9.5 days (median 6, range 1-54). Mean hospitalisation time in the Neurosurgical Department was 40.5 days (median 30, range 5-200) and mean rehabilitation time in Hornbaek was 195 days (median 166, range 51-474). The patient received in Hornbaek 3 years after injury was not included in these calculations. 
Table I Aetiology for traumatic spinal cord injuries in Greenland for patients admitted to the Rehabilitation Hospital in Hornbaek 1965 to 1986

$$
\text { Paraplegia Tetraplegia }
$$

\begin{tabular}{|c|c|c|c|c|c|}
\hline \multirow{2}{*}{ Aetiology } & & & \multirow[b]{2}{*}{ Total } \\
\hline & Incomplete & Complete & Incomplete & Complete & \\
\hline Attempted suicide & 2 & 5 & 0 & 0 & 7 \\
\hline Accidental shot & 1 & 3 & 0 & 0 & 4 \\
\hline Violence & 2 & 0 & 0 & 1 & 3 \\
\hline Fall to a level below & 2 & 1 & 2 & 1 & 6 \\
\hline Fall on same level & 0 & 0 & 2 & 1 & 3 \\
\hline Hit by moving object & 1 & 0 & 1 & 0 & 2 \\
\hline Sporting accident & 0 & 0 & 1 & 0 & 1 \\
\hline \multirow[t]{3}{*}{ Traffic accident } & 0 & 1 & 0 & 0 & 1 \\
\hline & 8 & 10 & 6 & 3 & 27 \\
\hline & & & & & 27 \\
\hline
\end{tabular}

\section{Aetiology}

The aetiology of the spinal cord injuries is shown in Table I. Six out of 7 suicidal attempts were jumps from buildings. Two out of 3 injuries following violence were likewise caused by falls. The sport accident was a fall during alpine skiing. Thus 15 out of the 27 injuries were caused by falls. The traffic injury was a motor cycle accident. According to the available case records 14 of the 27 injured were under the influence of alcohol at the time of injury.

\section{Neurology}

Two thirds of the patients were paraplegic, one third tetraplegic.

The neurological status, evaluated by use of the classification of Frankel et al. (1969) at admission to the neurosurgical department and at discharge from the Rehabilitation Hospital in Hornbaek, was found in 10 out of 27 patients $(37 \%)$ to improve during rehabilitation, i.e. they regained useful motor function (Frankel class D $+\mathrm{E}$ ). The remaining patients showed unchanged neurological status from admission to discharge, and 10 of these remained in Frankel class A.

\section{Social outcome}

Four patients were Danes, working temporarily in Greenland, and all remained in Denmark after completing rehabilitation. The social outcome for the 23 native Greenlandic patients is summarised in Table II, which shows that most social changes occur in the groups where no useful motor remission was experienced (Frankel class A-C) at discharge as these patients at the time of followup to a higher degree were living alone (14/15), were out of work (13/15) and had changed their residence after their injury (15/15). One patient, a high complete tetraplegic, is permanently resident in a hospital in Greenland. Four patients remained in Denmark after completing primary rehabilitation. The remaining 9 patients lived in houses or apartments with proper adjustments according to their disability.

One patient had died at the time of follow up aged 27 years; he had been 
Table II Social rehabilitation for patients with spinal cord injuries sustained in Greenland 1965 to 1986 , in relation to neurological level and completeness of lesion. Only those 23 patients brought up in and living in Greenland.

\begin{tabular}{|c|c|c|c|c|c|c|c|c|}
\hline \multirow[b]{2}{*}{$\mathbf{N}$} & & \multirow{2}{*}{$\begin{array}{l}\text { Frankel group } \\
\text { at discharge }\end{array}$} & \multicolumn{2}{|c|}{ Living without partner } & \multicolumn{2}{|c|}{ Working } & \multicolumn{2}{|c|}{ New residence a.a. } \\
\hline & & & b.a. & a.a. & b.a. & a.a. & Yes & No \\
\hline 4 & Tetraplegia & $\mathrm{A}-\mathrm{C}$ & 2 & 4 & 4 & 0 & 4 & 0 \\
\hline 2 & Tetraplegia & D-E & 0 & 0 & 2 & 1 & 1 & 1 \\
\hline 11 & Paraplegia & $\mathrm{A}-\mathrm{C}$ & 6 & 10 & 10 & 2 & 11 & 0 \\
\hline 6 & Paraplegia & D-E & 3 & 3 & 6 & 4 & 2 & 4 \\
\hline
\end{tabular}

b.a. $=$ before accident

a.a. $=$ after accident

living alone and was unemployed in Denmark. Death was caused by infection due to a large pressure sore.

\section{Discussion}

The incidence of traumatic SCI in Denmark has for the period 1975 to 1984 been estimated to be 9.2 per million per year (using the same admission criteria and including the Greenlandic material) (Biering-Sørensen, 1989), but from other parts of the world the incidence varies from 15 to 30 per million per year (Kurtzke, 1975). A precise calculation of the SCI incidence in Greenland is difficult, but our observed figures ( $29 \mathrm{SCI}$ in 22 years in a population of approximately 50000 ) corresponds to an incidence of 26 per million inhabitants per year, i.e. 3 times higher than that for the total Danish kingdom. The real incidence might be even higher, for example we have not received any patients from East-Greenland inhabited by approximately $10 \%$ of Greenland's total population. This part of Greenland is far less accessible and one could fear that some SCI patients as well as others with severe accidents do not survive transportation to hospital.

Overall $14 \%$ of registrated deaths in Greenland in 1984 were caused by accidents (Statistical Yearbook, 1986), among these there might well be cases in which SCI plays a significant role in the cause of death.

The observed SCI incidence of 26 per million per year seems remarkably high, as traffic accidents causing SCI are negligible in Greenland. Other causes do, however, make up for this and the number of suicide attempts draws attention.

In Greenland suicide is a common cause of death (58 out of 439 in 1984), only exceeded by malignancies and accidents (Statistical Yearbook, 1986).

This suicide frequency of more than $0.1 \%$ is very high and may be considered to be one of the regrettable social diseases that result from Greenland's colonisation-like relationship to Denmark.

The high incidence of accidental shots causing SCI shows that Greenland still is a society of hunters.

More paraplegics than tetraplegics were observed, this may be explained by the large number of SCI due to falls, as these typically lead to lesions in the thoracolumbar spine (Kurtzke, 1975). Furthermore, the accidents that often lead to tetraplegia (diving, traffic) are uncommon in Greenland. 
The neurological prognosis after SCI corresponds to what is found elsewhere (Bedbrook, 1982; Frankel, 1969).

Whilst in Denmark it is often possible to adjust the patient's living place to his/her disability, this is often impossible in Greenland, due to the geographical conditions with uneven highlands and mountains. These conditions, in addition to the Greenlandic society structure with hunting and fishing as the most important occupations, also accounts for the difficulties in returning to work after SCI.

\section{Acknowledgement}

We thank Chief of the District Health Services in Greenland Jørgen Bøggild for valuable assistance in collecting the follow-up data.

\section{References}

BEDBROOK GM, SAKAE T 1982 A review of cervical spine injuries with neurological dysfunction. Paraplegia 21: 321-333.

Biering-S $\phi$ Rensen F, Pedersen V, Clausen S 1989 Epidemiology of spinal cord lesions in Denmark. Paraplegia, in press.

Frankel HL, HaNCOCK DO, Hyslop G et al. 1969 The value of postural reduction in the initial management of closed injuries in the spine with paraplegia and tetraplegia. Paraplegia 7:179192.

KRAUS JF 1980 Injury to the head and spinal cord. The epidemiological relevance of the medical literature published from 1960 to 1978. Fournal of Neurosurgery 53:3-10.

KURTZKE JF 1975 Epidemiology of spinal cord injury. Experimental Neurology 48:163-236.

Pedersen V, Clausen S, Biering-S $\phi$ Rensen F 1988 The prognosis in cervical cord lesions. Ugeskrift for Laeger 150: 1162-1166.

Statistical Yearbook 1968, 1977, 1986. Danmarks statistik, Copenhagen. 